\title{
Avaliação "In Vitro" de Materiais Empregados no Vedamento do Terço Cervical da Obturação e Assoalho da Câmara Pulpar
}

\section{Evaluation "In Vitro" of Employed Stuff in the Vedamento of the Cervical Portion of the Fill- ing and Floor of the Chamber Pulpar}

\section{Carolina de Andrade Lima CHAVES}

Aluna do PROAC, área de concentração em Prótese - Faculdade de Odontologia de São José dos Campos - Universidade Estadual Paulista - UNESP - São José dos Campos - SP - Brasil

\section{Caroline Soares CAVALCANTI}

Cirurgiã - dentista graduada pela Faculdade de Odontologia de Caruaru - Associação Caruaruense de Ensino Superior ASCES - Caruaru -PE - Brasil

\section{João Manoel da SILVA FILHO}

Profo. Msc. do Departamento de Endodontia da Faculdade de Odontologia de Caruaru - Associação Caruaruense de Ensino Superior - ASCES - Caruaru - PE - Brasil

\author{
Anamaria Pessoa Pereira LEITE \\ Profa. Dra. da Disciplina de Endodontia da Faculdade de Odontologia de Caruaru -Associação Caruaruense de Ensino \\ Superior - ASCES - Caruaru - PE - Brasil
}

\begin{abstract}
Resumo
O presente estudo testou "in vitro", a capacidade vedante de três materiais em forma de película seladora, aplicada sobre o terço cervical das obturações e assoalho da câmara pulpar, imediatamente pós-obturação de canais radiculares, visando prevenir a microinfiltração coronária, através da interface parede dentinária / material obturador do canal radicular. Utilizou-se de quarenta molares humanos com raízes completamente formadas, os canais radiculares instrumentados pela técnica de Oregon, irrigados com solução de hipoclorito de sódio a $0,5 \%$ e obturados pela técnica clássica de condensação lateral. Após a limpeza da câmara pulpar e das superfícies dentais, impermeabilizaram-se coroas e raízes com a utilização do esmalte para unhas incolor. Os dentes foram divididos aleatoriamente em quatro grupos de dez dentes, sendo um grupo controle e três grupos experimentais. Diferentes materiais foram aplicados sobre o assoalho da câmara pulpar e terço cervical das obturações de cada grupo experimental: G1- Super Bonder; G2- Esmalte para unhas; G3- Primer \& Bonder 2.1; e G4- nenhum material foi aplicado. Logo após aplicação, os elementos dentários foram termociclados e imersos na tinta Nankin por um período de cinco dias. Em seguida foram então lavados, secos e o esmalte para unhas aplicado superficialmente, removido. Os espécimes foram então descalcificados, desidratados e diafanizados sendo, posteriormente, examinados por três examinadores previamente calibrados. Os resultados, após testes estatísticos, segundo técnica descritiva e inferencial (Kruskal-Wallis e Comparação Pareada), determinaram que não houve diferença estatisticamente significante entre os três materiais. Os produtos, esmalte para unhas e Super Bonder mostraram-se estatisticamente superiores ao grupo controle.
\end{abstract}

\section{Palavras-chaves}

Microinfiltração; selamento coronário; obturação. 


\section{INTRODUÇÃo}

A necessidade de selamento coronário para o êxito do tratamento endodôntico foi confirmado por vários autores como Leonard et. al. ${ }^{4}$ (1996), Magura et. al. ${ }^{7}$ (1991), Saunders \& Saunders ${ }^{15}$ (1993), Souza et. al. ${ }^{17}$ (2005) e Uçtash \& $\operatorname{Tinaz}^{19}$ (2000) alertando a comunidade científica.

Os insucessos clínicos relacionados à microinfiltração poderiam ser reduzidos se houvesse materiais restauradores que selassem eficazmente a dentina, entretanto os materiais de uso odontológico não são inteiramente eficazes a este requisito, permitindo diferentes graus de infiltração ${ }^{9,19}$.

Segundo Pasinatto \& $\operatorname{Atta}^{10}$ (2004), a microinfiltração é um fenômeno dinâmico que permite a passagem de fluidos orais e produtos bacterianos através da interface dente / restauração tendo-se como resultado efetivo, as patologias periapicais. A microinfiltração relacionada à Endodontia, diz respeito à movimentação de fluídos e microrganismos através da interface parede dentinária / material obturador.

Dentre alguns fatores que podem influenciar na ocorrência da infiltração coronária, têm-se: a) preparo e a limpeza dos canais radiculares; b) a técnica usada para obturar os canais radiculares; c) o tipo do cimento obturador; d) viscosidade e solubilidade do cimento obturador e; e) o tempo para que ocorra a percolação total da obturação dos canais ${ }^{12}$.

Leonard et. $\mathrm{al}^{5}$. (1996) confirmou a existência de infiltração apical em maior ou menor grau em todos os tipos de cimentos obturadores testados.

Baseado nesta verificação faz-se necessário à escolha de um cimento obturador que possua baixo grau de solubilidade, pois a mesma acarreta inflamação após obturação ${ }^{14}$.

O selamento da porção coronária de molares é de fundamental importância, pois não apenas estará protegendo a obturação dos canais radiculares, como igualmente, os possíveis canais acessórios localizados no assoalho da câmara pulpar, cuja contaminação poderá provocar alterações inflamatórias na região de furca, em decorrência da infiltração de microorganismos e toxinas provenientes da câmara pulpar ${ }^{2,14}$.

Ray \& Trope $^{13}$ (1995), afirmaram que o selamento e a qualidade do tratamento endodôntico são igualmente importantes para a saúde dos tecidos perirradiculares, pois apenas uma boa obturação não é suficiente para combater a infiltração coronária.

Baseado nessas considerações esse estudo se propôs avaliar "in vitro" a capacidade de vedamento de três materiais, em forma de película seladora, aplicada sobre o terço cervical das obturações e assoalho da câmara pulpar de molares humanos recém-extraídos, imediatamente pós-obturação de canais radiculares, visando prevenir a microinfiltração coronária, através da interface parede dentinária / material obturador de canal radicular.

\section{Materias e Métodos}

Foram utilizados quarenta molares humanos recém-extraídos, após aprovação no comitê de ética no CEP/ASCES $n^{\circ} 027 / 05$, com coroas íntegras ou parcialmente íntegras e raízes completamente formadas. Após a exodontia, os dentes coletados permaneceram imersos em solução de hipoclorito de sódio a $0,5 \%$ para a remoção dos restos teciduais, por um período de $24 \mathrm{hs}$, sendo então lavados em água corrente, transferidos e armazenados em solução de timol a $0,1 \%$ à temperatura ambiente de $25^{\circ} \mathrm{C}\left(+/-2^{\circ} \mathrm{C}\right)$, até $\mathrm{o}$ momento da realização do experimento.

Após a abertura coronária para fins endodônticos, foi realizada a patência do canal radicular com o auxílio de lima K \# 10 (Maillefer Insttrymentos S.A. - Swiss) com o propósito de promover uma completa limpeza do 1/3 apical da raiz. A odontometria e o limite apical de instrumentação foram estabelecidos através da introdução de uma lima tipo K \# 10 (Maillefer Instruments S.A - Swiss), até a visualização da sua ponta ativa ao nível do forame apical. Da medida obtida, foi subtraído $1,0 \mathrm{~mm}$, determinando para cada canal o seu comprimento de trabalho (ct).

Os canais radiculares foram instrumentados de acordo com a Técnica de Oregon, com alargamento cervical, utilizando-se brocas Gates-Gliden \#1 e \#2 (Maillefer Instruments S. A.) e preparo apical com lima tipo K \# 40 (Maillefer Instruments S. A. - Swiss). A instrumentação foi considerada satisfatória, quando um espaçador digital \# B (Maillefer Instruments S. A.) penetrar livremente a $1,0 \mathrm{~mm}$ do comprimento de trabalho previamente determinado. Cada canal foi irrigado com $40 \mathrm{ml}$ de solução de hipoclorito de sódio a $0,5 \%$, durante toda a fase de instrumentação. Quando da troca de limas, a patência do canal radicular foi mantida através da utilização de um instrumento tipo K \# 10 (Maillefer Instruments S. A. - Swiss), em toda a sua extensão.

Terminado o preparo químico-mecânico, os canais forma secos com cone de papel absorvente (Dentsply-Brasil) e obturados no comprimento de trabalho (ct) pré-estabelecido, através da Técnica 
Clássica de Condensação Lateral. Foram utilizados como materiais obturadores o cimento endodôntico Sealer 26 (Dentsply-Brasil) e cones de guta percha principais \# 40 e secundários (EndoPoint-Brasil). O excesso de material obturador foi removido até o nível da entrada do canal, utilizando-se um instrumento aquecido ao rubro e a completa limpeza da câmara pulpar foi realizada com álcool isopropílico $\left(70^{\circ} \mathrm{GL}\right)$ embebido em esponja.

Após a limpeza e a secagem das superfícies externas dos dentes e das câmaras pulpares, foram feitas as impermeabilizações externas das coroas e raízes através da aplicação de duas camadas de esmalte para unhas cremoso incolor (Risqué-Brasil) nas superfícies externas dentais, exceto $1,0 \mathrm{~mm}$ ao redor da abertura coronária, com o objetivo de evitar a infiltração de líquidos através dos canais laterais, delta apical, trincas de esmalte, ou, ainda, pelo forame apical.

Os dentes foram divididos em quatro grupos de dez dentes cada, escolhidos aleatoriamente. Em cada um dos três grupos experimentais, diferentes materiais seladores foram aplicados sobre o assoalho da câmara pulpar e topo coronário da obturação endodôntica com o auxílio de aplicadores descartáveis (Optimum-Brasil).

Assim, no grupo 1 foi aplicado Super Bond (Loctite-Brasil); no grupo 2 esmalte para unha incolor (Risque-Brasil); no grupo 3 adesivo Primer e Bonder 2.1 (Denstply-Brasil)e no grupo 4 nenhum material foi colocado para servir como controle (Tabela 1 ).

Cada dente recebeu a aplicação de apenas uma camada do material, seguindo as normas do fabricante.

Após a aplicação e secagem dos materiais seladores, os dentes foram submetidos 500 ciclos térmicos, em uma máquina de termociclagem (Ética - São Paulo) com temperatura variando $5^{\circ} \mathrm{C}_{-}+2^{\circ} \mathrm{C}$ e $55^{\circ} \mathrm{C}_{-}+2^{\circ} \mathrm{C}$ com intervalos de tempo de 30 segundos em cada temperatura, totalizando um período de tempo de 60' para cada ciclo.

Posteriormente, os dentes foram imersos em tinta Nankim contidas em placa de Petri $(10 \mathrm{~cm} \mathrm{X} 2 \mathrm{~cm})$ por cinco dias.

Finalizando o tempo de imersão dos espécimes, foram lavados em água corrente por uma hora, a fim de se remover os vestígios do corante. Após esta etapa, o esmalte para unhas aplicado na superfície externa dental, foi removido através de raspagem com lâmina de bisturi \# 15 (BD-Brasil), completada com o uso de removedor de esmaltes (Rishon-Brasil) embebido em algodão.

Os dentes foram descalcificados em Ácido Clorídrico a 5\% por um período de setenta e duas horas, até demonstrarem consistência borrachóide, em seguida, lavados em água corrente por quatro horas. Posteriormente, foram desidratados em uma bateria de álcool ascendente a $70^{\circ} \mathrm{GL}, 80^{\circ} \mathrm{GL}$ e $90^{\circ} \mathrm{GL}$ por um período de quatro horas em cada banho, e doze horas em álcool absoluto, com troca a cada quatro horas.

Estando os dentes descalcificados e desidratados, esses foram colocados em recipiente contendo Salicilato de Metila a fim de serem diafanizados.

Os dentes foram examinados, por 3 avaliadores previamente calibrados, com o auxilio de uma lupa esterioscópica em aumento de 10X, e o nível de infiltração avaliados e anotados de acordo com os seguintes critérios:

- Grau 0: Nenhuma penetração do corante;

- Grau 1: Penetração do corante apenas no $1 / 3$ cervical do canal radicular;

- Grau 2: Penetração do corante no 1/3 médio do canal radicular;

- Grau 3: Infiltração em toda a extensão do canal radicular (até o $1 / 3$ apical).

\section{Tabela 1 - Grupos estudados e materiais seladores aplicados no assoalho da câmara pulpar e terço cervical da obturação endodôntica.}

\begin{tabular}{lll}
\hline GRUPOS & MATERIAIS & PROCEDÊNCIAS \\
\hline GRUPO 1 & Cianocrilato ( Super Bonder) & Loctite Brasil Ltda. \\
GRUPO 2 & Nitrocelulose (esmalte para unhas) & Niasi S. A. \\
GRUPO 3 & Resina Flúida (Primer \& Bonder 2.1.) & Dentsply Brasil \\
& Grupo Controle positivo & \\
\hline
\end{tabular}


Após a análise, dentes representando os níveis de infiltração adotado neste estudo foram fotografados. Para tanto, os dentes selecionados foram imersos em Salicilato de Metila contido na placa de Petri $(10 \mathrm{~cm}$ $\mathrm{X} 2 \mathrm{~cm}$ ), sendo esta colocado sob um negatoscópio horizontal.

E com o objetivo de verificar o grau de coincidência entre os pares de examinadores, foram obtidos os escores de coincidência de Kappa. Este teste equivale a verificar se as avaliações entre dois examinadores são independentes ou não.

\section{Resultados}

Os resultados obtidos em todas as avaliações de todos os examinadores segundo o grupo estão contidos na Tabela 2.

Para a avaliação dos resultados foram utilizadas as técnicas de estatística descritiva e inferencial. As técnicas de estatística descritiva incluíram distribuições absolutas e percentuais dos graus de infiltração de todas as avaliações e dos graus medianos obtidos a partir das três avaliações realizadas pelos três examinadores para o mesmo dente demonstrado na Tabelas 3. As técnicas de estatística inferencial envolveram a aplicação do teste de Kruskal-Wallis e das Comparações Pareadas do referido teste para detectar que grupos apresentam diferenças significantes (Tabela 4 e 5). Estes testes revelaram a existência de diferença estatística entre os grupos 1 e 2 com o 4, a nível de significância de $5 \%(\alpha=0,05)$, mas não foram demonstradas diferenças estatisticamente significantes entre o grupo 1 e 3 (Tabela 4). Para verificar o grau de coincidência entre os examinadores foi utilizado os escores de coincidência de Kappa. O resultado indicou coincidência moderada para os examinadores 1 e $2(55 \%)$ e boa, entre os examinadores 2 e 3 (80\%), sendo rejeitada a hipótese que o Kappa populacional é nulo $(\mathrm{p}<0,05)$.

\section{Discussão}

Com base nos resultados, verifica-se que nenhum dos materiais testados no presente estudo foi capaz de impedir a infiltração em $100 \%$ dos casos.

Apesar da maioria dos trabalhos sobre microinfiltração serem realizados em dentes unirradiculares, segundo Leonard et. al. ${ }^{5}$ (1996), Magura et. al. ${ }^{7}$ (1991) e Uçtash \& $\operatorname{Tinaz}^{19}$ (2000), este estudo torna-se mais crítico em molares humanos devido a existência de canais acessórios localizados no assoalho da câmara pulpar, os quais podem promover a percolação de infiltrados de microrganismos e toxinas na região de furca, provocando alterações inflamatórias nessa região ${ }^{14,19}$.

Quando do estudo sobre microinfiltração, faz-se necessário o emprego da ciclagem térmica. Este método simula as mudanças de temperatura ocorridas na cavidade oral, já que tais alterações poderiam influenciar no poder de vedamento dos materiais restauradores, como já verificado por alguns autores $3,8,10,14$.

Taylor \& Lynch $^{18}$ (1992), afirmam que é necessário a utilização de corantes estáveis, em estudos sobre microinfiltração, para que não ocorra erro na interpretação dos resultados. Por este motivo, optouse então pela utilização da tinta Nankin como corante orgânico, uma vez que o mesmo comporta-se de maneira adequada quando da realização da diafanização, estando de acordo com Pécora ${ }^{11}$ (1986).

Tabela 2 - Avaliação do grau de infiltração para todas as avaliações dos três examinadores

\begin{tabular}{|c|c|c|c|c|c|c|c|c|c|c|}
\hline \multirow{3}{*}{ Grupo } & \multicolumn{10}{|c|}{ Grau } \\
\hline & \multicolumn{2}{|l|}{0} & \multicolumn{2}{|l|}{1} & \multicolumn{2}{|l|}{2} & \multicolumn{2}{|l|}{3} & \multicolumn{2}{|c|}{ TOTAL } \\
\hline & $\mathrm{n}$ & $\%$ & $\mathrm{~N}$ & $\%$ & $\mathrm{n}$ & $\%$ & $\mathrm{n}$ & $\%$ & $\mathrm{~N}$ & $\%$ \\
\hline 1 & 18 & 60,0 & 12 & 40,0 & - & - & - & - & 30 & 100,0 \\
\hline 2 & 20 & 66,7 & 8 & 26,7 & 1 & 3,3 & 1 & 3,3 & 30 & 100,0 \\
\hline 3 & 15 & 50,0 & 11 & 36,7 & 4 & 13,3 & - & - & 30 & 100,0 \\
\hline 4 (controle positivo) & 1 & 3,3 & 22 & 73,3 & 1 & 3,3 & 6 & 20,0 & 30 & 100,0 \\
\hline Grupo total & 54 & 45,0 & 53 & 44,2 & 6 & 5,0 & 7 & 5,8 & 120 & 100,0 \\
\hline
\end{tabular}


Tabela 3 - Avaliação dos graus medianos

\begin{tabular}{|c|c|c|c|c|c|c|c|c|c|c|}
\hline \multirow{3}{*}{ Grupo } & \multicolumn{10}{|c|}{ Grau mediano } \\
\hline & \multicolumn{2}{|l|}{0} & \multicolumn{2}{|l|}{1} & \multicolumn{2}{|l|}{2} & \multicolumn{2}{|l|}{3} & \multicolumn{2}{|c|}{ TOTAL } \\
\hline & $\mathrm{n}$ & $\%$ & $\mathrm{~N}$ & $\%$ & $\mathrm{~N}$ & $\%$ & $\mathrm{n}$ & $\%$ & $\mathrm{~N}$ & $\%$ \\
\hline 1 & 6 & 60,0 & 4 & 40,0 & - & - & - & - & 10 & 100,0 \\
\hline 2 & 7 & 70,0 & 3 & 30,0 & - & - & - & - & 10 & 100,0 \\
\hline 3 & 6 & 60,0 & 3 & 30,0 & 1 & 10,0 & - & - & 10 & 100,0 \\
\hline 4 (controle positivo) & - & - & 8 & 80,0 & - & - & 2 & 20,0 & 10 & 100,0 \\
\hline Grupo total & 19 & 47,5 & 18 & 45,0 & 1 & 2,5 & 2 & 5,0 & 40 & 100,0 \\
\hline
\end{tabular}

Tabela 4 - Avaliação da média dos postos

\begin{tabular}{lll}
\hline Grupo & Média dos Postos & Valor $p$ \\
\hline 1 & 17,40 & $\mathrm{p}(1)=0,0046^{\star}$ \\
2 & 15,55 & \\
3 & 18,35 & \\
4 & 30,70 & \\
\hline
\end{tabular}

(*) - Associação significante ao nível de 5,0\%.

(1) - Através do teste de Kruskal-Wallis.
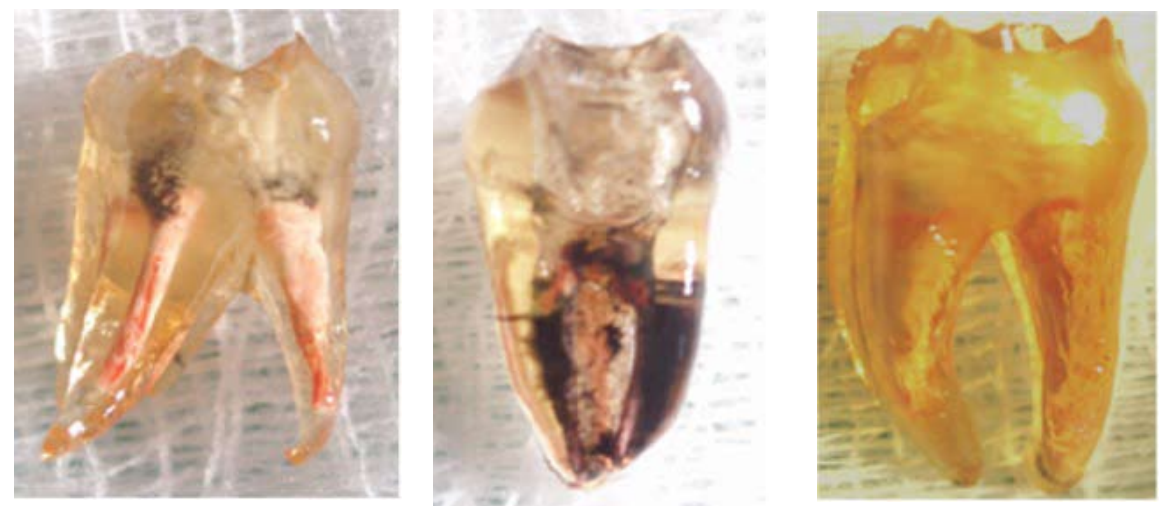

Figura 1:Nivel 1 Figura 2: Nivel3 Figura 3: Nivel zero 
O método de análise selecionado para avaliar o padrão de penetração do corante foi a diafanização, por ser uma técnica simples e não destrutiva, que permite o estudo da anatomia interna e a verificação da qualidade da instrumentação e obturação dos canais radiculares. Fato esse defendido por Pécora ${ }^{11}$ (1986).

Tomando por base as sugestões de Beckham et. al. ${ }^{1}$ (1993), optou-se pelo emprego de materiais de aspecto físico semelhantes e possuidores de boa fluidez; o que facilitaria o escoamento do material durante sua aplicação. Leite ${ }^{4}$ (1997), em um estudo "in vitro" avaliou quatro materiais, sendo eles: esmalte para unhas; Super Bonder; Scothbond MP+ e o Heliobond, tendo como objetivo o vedamento do assoalho da câmara pulpar e topo da obturação dos canais radiculares.

Serra et. $\mathrm{al}^{16}$ (1994), em um estudo "in vitro", onde foram testados protetores superficiais para o cimento de ionômero de vidro, constataram que o esmalte para unhas foi o material que apresentou o melhor desempenho. Avaliando os resultados do presente estudo, com relação à utilização do esmalte para unhas, como agente vedador de assoalho da câmara pulpar e topo da obturação do canal radicular, pode-se observar na Tabela 2 que esse material demonstrou em $66,7 \%$ das repetições o nível zero de infiltração da tinta Nankin. Tais achados corroboram com os verificados por Serra et. al. ${ }^{16}$ (1994) os quais justificam a eficácia da proteção superficial devido a resistência à desintegração, a sua natureza hidrófoba e a sua baixa permeabilidade e viscosidade.

Em relação ao trabalho de Leite $^{4}$ (1997), o Super Bonder apresentou-se ligeiramente melhor do que o esmalte para unhas, mesmo eles não diferindo estatisticamente. Pode-se inferir então que, o eugenol livre decorrente do cimento obturador do tipo Grossman, usado naquele estudo, tenha interferido na polimerização completa do esmalte para unhas.

Leite $^{4}$ (1997) \& Souza ${ }^{17}$ (2005), verificaram que o Super Bonder não apresentou resultados estatisticamente diferentes dos outros materiais testados, tal relato é concordante com o verificado no presente estudo, onde se pode observar na Tabela 2, que o mesmo impediu a infiltração do corante em $60 \%$ dos espécimes. Contudo, mostrou-se mais efetivo na redução da microinfiltração se comparado com o grupo controle.

Buscando materiais que controlasse a infiltração coronária Leite ${ }^{4}$ (1997), avaliou adesivos de quarta geração, o Scothbond MP+ e o Heliobond, verificando que os mesmo não foram eficazes no impedimento da ocorrência da infiltração coronária. No presente estudo, foi testado um adesivo de quinta geração, o Primer \& Bonder 2.1, o qual mostrou-se estatisticamente superior ao grupo controle, como também foi afirmado por Souza et. al $^{17}$ (2005); porém não diferiu estatisticamente dos demais materiais testados, como se pode observar na Tabela 2, estando em concordância com os achados do autor supracitado. Supõe-se que tal afirmativa poderia ser justificada uma vez que as duas gerações de adesivos seguem o mesmo princípio: condicionar a dentina, remover o smear layer, desmineralizar a dentina tubular e inter tubular, e promover a desfosforalização do colágeno dentinário, permitindo o uso do primer hidrofílico.

Neste trabalho empregou-se como material obturador do sistema de canais radiculares o cimento resinoso contendo hidróxido de cálcio, o Sealer 26. A escolha desse material foi igualmente realizada visando a não interferência na polimerização dos materiais resinosos, conforme Macchi $^{6}$ (1991), já que possivelmente poderia existir uma similaridade química entre os materiais testados e o cimento empregado. Contudo, baseado na Tabela 2 pode-se comprovar que o Primer \& Bonder 2.1, mesmo sendo um material odontológico, onde foram realizadas todas as etapas pré-estabelecidas pelo fabricante, não foi verificada diferença estatisticamente superior em relação aos outros materiais testados.

A motivação desta pesquisa baseou-se na busca de minimizar a infiltração coronária nas situações onde as restaurações definitivas não fossem realizadas de imediato. Apesar de já existirem materiais comprovadamente indicados para esta finalidade, dentre eles o cimento de Ionômero de Vidro, entende-se que por ser um material de custo relativamente elevado, o mesmo não se faz existente em serviços públicos e clínicas populares.

\section{Conclusões}

Em função das condições em que este estudo foi realizado e dos resultados obtidos, pode-se concluir que nenhum dos materiais testados, no presente estudo, apresentou-se capaz de impedir em 100\% dos casos, a ocorrência da microinfiltração coronária em longo prazo. Contudo, o esmalte para unhas e o Super Bonder foram efetivos no impedimento da infiltração, nos valores de $60 \%$ e $66,7 \%$ para o nível zero dos escores, respectivamente. 


\section{Abstract}

The present study tested "in vitro" the sealing ability of three materials, as barriers materials, applied over the top of the obturation and the floor of the pulp chamber, imediatly after sealer of root canal, with the purpose of avoid the coronal microleakage, through the root filling/walls of the root canal interface. Forty humans molars with complete, or parcially complete, crowns and root completely formed were used. The root canals were shaped by the Oregon technique, irrigated with NaOCL $0,5 \%$ and obturated according with the classic technique of lateral condensation. After the cleaning of the pulp chamber and dentals surfaces, the external portion of the crow and root were sealed with the use of colorless nail polish. After that, teeth were divided in random form in four groups of ten teeth. Different materials were applied on the pulp chamber and top of the obturation of each experimental group: G1 - Super Bonder. G2- nail polish. G3- Primer \& Bonder, G4- no material was used. After the washed, the teeth elements were thermociclyng and, soon after that, immersed in Nankin for five days. The specimen were washed, dried and the nail polish that was superficially used was removed. Teeth were descalcified, dehydrated and cleared and then, they were examined by three previously calibrated examiners. Later, teeth representing the infiltration levels were photographed. The results, after statistical tests, according to the descriptive and inferencial technique (Kruskal-Wallis and Pairwise Comparaion test), had determined there were no difference statisticly significant among the three materials. The products, nail polish and Super Bonder happened to be statisticly superiors.

\section{UNITERMS}

Microleakage; coronal sealing; obturation.

\section{ReferênCIAS BIBLIOGRÁFICAS}

1.Beckham BM, Anderson RW, Morris CF. An evaluation of three materials as a barrier to coronal microleakage in endodontically treated teeth. $\mathrm{J}$ Endod. 1993;19:338-91.

2.Carman JE, Wallace J. An in Vitro comparison of microleakage of restorative materials in the pulp chambers of human molar teeth. J Endod. 1994;20(12):571-5.

3.Crim GA, Swartz ML, Phillips RW. Comparison of four thermocycling techniques. J Prosthet Dent. 1985;53:50-3.

4.Leite APP. Avaliação in vitro de películas seladoras na prevenção da microinfiltração coronária, pós-obturação de canais radiculares. [dissertação] Campinas : Universidade Estadual de Campinas; 1997.

5.Leonard JE, Gukman JL, Guo IY. Apical and coronal selal of roots obturated with a detin bonding agente and resin. Int Endod J. 1996;29:76-83.

6.Macchi RL, Caputo MA, Herrera CL, Cebada FR, Kohen S. Influenece of endodontically materials on the bonding of composite resin dentin. Endod Dental Traumatol. 1991;8:26-29.

7.Magura ME, Kafrawy AM, Brown CEJ, Newton CW. Human saliva coronal microleakage in obturated root canals: an in vitro study. J Endod. 1991 July 1;17(7): 324-30.

8. Momoi Y, Nakano Y, Komno A, Asanuma A, Yanagisawa, K. Gradual increase in marginal leakage of resin composite restorations with thermal stress. J Dent Res. 1990; 69:1659-63.

9. Pashley DH. Clincal considerations of microleakage. J Endod. 1990;16:70-77.

10.Pasinatto FB, Atta MT. Estudos de microinfilração: análise crítica da metodologia. Rev JBD. 2003;2(8):207-15.

11.Pécora JD, Saviol RN, Vansan CP, Gariba SR, Ferreira CW.The new method for making transparent teeyh. Rev Fac Odontol Ribeirão Preto 1986 jan / jun; 23(1):1-5.
12.Pécora JD. Avaliação da estabilidade dimensional de alguns cimentos seladores provisórios prontos para uso. Rev Odontol Brasil Central 1996;(6):16-8.

13.Ray HA, Trope M. Periapical status of endodontically treated teeth in relation to the technical quality of the root filling and the coronal restoration. Int Endod J. 1995; 28:12-8.

14.Saunders EM, Saunders HP. Assesmente of leakage in the restored pulp chamber of endodonticaley trated multirooted teeth. Int Endod J. 1990;2:28-33.

15.Saunders EM, Saunders HP. Cornal leakagae as a cause if failure in root canal therapy: a review. Endod Dent Traumatol. 1993;10:105-8.

16.Serra MC, Navarro MF, Freitas SF, Carvalho RM, Cury JA, Retief DH. Glass ionomer cement surface protection. Am J Dent 1994;7:2003-6.

17.Souza FDS, Pécora JDP, Silva R G. The effect on coronal leakage of liquid adhesive application over root fillings after smear layer removal with EDTA or Er: YAG laser. Oral Surg Oral Med Oral Pathol Oral Radio Endod. 2005;99:125-8.

18. Taylor MJ, Lynch E. Microleakage. J Dent. 1992;20:3-10.

19.Uçtash MB, Tinaz AC. Microleakage of different types of temporary restorative materials used in endodontics. J Oral Scien. $2000 ; 42(2) 63-7$

Recebido em: 31/08/06 Aprovado em: 01/09/07

Carolina de Andrade Lima Chaves Endereço: Av. Francisco Jose Longo, n 555, apt. 1306, São Dimas, São Jose dos Campos - São Paulo- SP. Cep: 12245-000. Fone: (12) 8111-9719. e-mail: carol_chaves1@ hotmail.com. 